Short Communication

\title{
On the impact of $\mathrm{Cu}$ dispersion on $\mathrm{CO}_{2}$ photoreduction over $\mathrm{Cu} / \mathrm{TiO}{ }_{2}$
}

\author{
Dong Liu ${ }^{a}$, Yolanda Fernández ${ }^{\text {a,b }}$, Oluwafunmilola Ola ${ }^{a}$, Sarah Mackintosh ${ }^{\text {a }}$, Mercedes Maroto-Valer ${ }^{\text {a,* }}$, \\ Christopher M.A. Parlett ${ }^{c}$, Adam F. Lee ${ }^{\text {c,* }}$, Jeffrey C.S. Wu ${ }^{\text {d,* }}$ \\ a Center for Innovation in Carbon Capture and Storage (CICCS), Faculty of Engineering, University of Nottingham, UK \\ ${ }^{\mathrm{b}}$ Instituto Nacional del Carbón, CSIC, Apartado 73, 33080, Oviedo, Spain \\ c Cardiff Catalysis Institute, School of Chemistry, Cardiff University, Cardiff CF10 3AT, UK \\ d Department of Chemical Engineering, National Taiwan University, Taipei, 10617, Taiwan
}

\section{A R T I C L E I N F O}

\section{Article history}

Received 14 November 2011

Received in revised form 9 March 2012

Accepted 16 March 2012

Available online 27 March 2012

\section{Keywords:}

Photocatalysis

Titania

$\mathrm{CO}_{2}$

Copper

Methane

\section{A B S T R A C T}

A family of $\mathrm{Cu} / \mathrm{TiO}_{2}$ catalysts was prepared using a refined sol-gel method, and tested in the photocatalytic reduction of $\mathrm{CO}_{2}$ by $\mathrm{H}_{2} \mathrm{O}$ to $\mathrm{CH}_{4}$ using a stirred batch, annular reactor. The resulting photoactivity was benchmarked against pure $\mathrm{TiO}_{2}$ nanoparticles (synthesised by an identical sol-gel route). $\mathrm{CO}_{2}$ photoreduction exhibited a strong volcano dependence on $\mathrm{Cu}$ loading, reflecting the transition from 2-dimensional CuOx nanostructures to 3-dimensional crystallites, with optimum $\mathrm{CH}_{4}$ production observed for $0.03 \mathrm{wt} . \% \mathrm{Cu} / \mathrm{TiO}_{2}$.

(C) 2012 Elsevier B.V. Open access under CC BY license.

\section{Introduction}

The natural environment is well-versed in maintaining an equilibrium between carbon dioxide $\left(\mathrm{CO}_{2}\right)$ fixed through photosynthesis, and that released into the atmosphere via normal biochemical processes. However, this natural equilibrium has been strongly perturbed over the past few centuries through increased $\mathrm{CO}_{2}$ emissions arising from fossil fuel combustion. The consequent dramatic rise in atmospheric $\mathrm{CO}_{2}$ concentrations is well documented as the major contributor to ongoing climate change [1]. The most promising strategies proposed to slow, and eventually reverse, these rising $\mathrm{CO}_{2}$ emissions are a switchover to renewable energy sources, or implementing carbon capture and storage technologies (CCS) [2] alongside conventional chemical processes. Direct $\mathrm{CO}_{2}$ utilisation as a chemical feedstock (notably for methane or methanol production) remains poorly exploited by current industrial processes, hence there exists great potential for new clean technologies for largescale $\mathrm{CO}_{2}$ fixation [3].

$\mathrm{CO}_{2}$ photoreduction is one such promising method for ameliorating atmospheric $\mathrm{CO}_{2}$ levels, while simultaneously providing energyrich or chemically useful products such as $\mathrm{CO}$, methane $\left(\mathrm{CH}_{4}\right)$, methanol $\left(\mathrm{CH}_{3} \mathrm{OH}\right)$, formaldehyde $(\mathrm{HCHO})$ or formic acid $(\mathrm{HCOOH})$. A major challenge to such chemistry remains the development of efficient photocatalysts for direct $\mathrm{CO}_{2}$ photoreduction offering high quantum yields, activity and selectivity. $\mathrm{TiO}_{2}$ is widely used in photocatalysis due to it's low cost

\footnotetext{
* Corresponding authors. Tel.: +44 29208 74778; fax: +44 2920874030 . E-mail address: leeaf@cardiff.ac.uk (A.F. Lee).
}

and toxicity, thermal stability and photo-response under UV irradiation, and thus may be viewed as a potential candidate for $\mathrm{CO}_{2}$. However, the highest $\mathrm{CO}_{2}$ photoreduction rate achieved using unpromoted $\mathrm{TiO}_{2}$ is only $25 \mu \mathrm{mol} . \mathrm{gcat}_{\mathrm{cat}}^{-1} \cdot \mathrm{hr}^{-1}[4,5]$, and consequently too low for industrial commercialisation. Methods to modify the titania band gap, such as $\mathrm{N}$-doping, or the addition of metal or oxide promoters to promote separation of photo-excited charge carriers and increase their lifetime for reaction with adsorbates, have both shown promise as routes to improve $\mathrm{CO}_{2}$ photoreduction activity [6-8]. However, to date, there has been little effort to optimise promoter loadings or understand their impact upon $\mathrm{TiO}_{2}$ catalysed $\mathrm{CO}_{2}$ photoreduction. Here we systematically explore the influence of $\mathrm{Cu}$ promotion via incorporation during sol-gel synthesis, upon photocatalytic $\mathrm{CH}_{4}$ production from $\mathrm{CO}_{2}$, and demonstrate that the resulting $\mathrm{Cu}_{2} \mathrm{O}$ dispersion plays a critical role in regulating the photocatalytic performance of $\mathrm{Cu} / \mathrm{TiO}_{2}$, wherein highly-dispersed (likely 2dimensional islands) $\mathrm{Cu}_{2} \mathrm{O}$ nanostructures maximise the $\mathrm{CH}_{4}$ yield.

\section{Experimental}

\subsection{Catalyst preparation}

Pure and copper loaded $\mathrm{TiO}_{2}$ were prepared by a modified sol-gel method adapted from Wu et al. [9] employing titanium (IV) n-butoxide ( Ti $\left(\mathrm{OC}_{4} \mathrm{H}_{9}\right)_{4}$, Acros Organics, 99\%) and copper (II) chloride $\left(\mathrm{CuCl}_{2} \cdot 2 \mathrm{H}_{2} \mathrm{O}\right.$, Certified AR, 99\%) precursors. To provide the stoichiometric amount of water for hydrolysis of the titanium precursor, $0.02 \mathrm{~mol}$ of $\mathrm{Ti}\left(\mathrm{OC}_{4} \mathrm{H}_{9}\right)_{4}$ was mixed with $0.08 \mathrm{~mol}$ of n-butanol $\left(\mathrm{C}_{4} \mathrm{H}_{9} \mathrm{OH}\right.$, Certified $\mathrm{AR}$, 99.5\%) and $0.08 \mathrm{~mol}$ of acetic acid $\left(\mathrm{CH}_{3} \mathrm{COOH}\right.$, Acros Organics, Glacial $\left.99.8 \%\right)$. 
Cu-loaded $\mathrm{TiO}_{2}$ was synthesised by pre-dissolving the desired amount of copper precursor (to provide $0.01-0.3 \mathrm{wt} . \% \mathrm{Cu} / \mathrm{TiO}_{2}$ ) in the $0.08 \mathrm{~mol}$ $\mathrm{n}$-butanol in order to achieve uniform copper incorporation throughout the titania support. Upon mixing the $\mathrm{Ti}\left(\mathrm{OC}_{4} \mathrm{H}_{9}\right)_{4}$ with n-butanol and acetic acid, esterification of the latter two chemicals resulted in slow water release and $\mathrm{Ti}\left(\mathrm{OC}_{4} \mathrm{H}_{9}\right)_{4}$ hydrolysis [10] which was complete after $6 \mathrm{~h}$. The resulting sol-gel was placed in a chamber furnace and heated at $3{ }^{\circ} \mathrm{C} \cdot \mathrm{min}^{-1}$ to $150{ }^{\circ} \mathrm{C}$ and held for $2 \mathrm{~h}$ to dry the precursor. The temperature was then ramped at $5^{\circ} \mathrm{C} \cdot \mathrm{min}^{-1}$ to $500{ }^{\circ} \mathrm{C}$ and held for $1 \mathrm{~h}$ to remove residual hydrocarbons and crystallise the titania. Samples were then ground by mortar and pestle for 20 min into powder form prior to $\mathrm{CO}_{2}$ photoreduction tests.

\subsection{Catalyst characterization}

The resulting titanias were analysed by powder X-ray diffraction (XRD, Hiltonbrooks) to identify the associated crystal phases. Analyses were conducted using $\mathrm{Cu} \mathrm{K}_{\alpha}$ radiation at $1.5406 \AA$ over $2 \vartheta=5^{\circ}$ $65^{\circ}$ at $2^{\circ} / \mathrm{min}$. Crystallite sizes were estimated from line broadening using the Scherrer equation [11]. Elemental analysis of the metal loaded $\mathrm{TiO}_{2}$ catalysts was performed via ICP-MS (Thermo-Fisher Scientific X-series $\left.{ }^{\mathrm{II}}\right)$. The surface composition [12] and chemical environment was evaluated by X-ray photoelectron spectroscopy (XPS) on a Kratos AXIS HSi instrument using a $\mathrm{Mg} \mathrm{K}_{\alpha}$ excitation source and equipped with a charge neutraliser and magnetic focusing lens. Particle morphology was examined by transmission electron microscopy (TEM, JEOL 2100F, $200 \mathrm{kV}$ ) with analysis using a Gatan Orius camera and Image $1.43 \mathrm{u}$ software. Total (BET) surface areas were determined by $\mathrm{N}_{2}$ porosimetry using an ASAP 2020 instrument (Micromeritics); samples were dried at $80^{\circ} \mathrm{C}$ and evacuated by vacuum overnight prior to analysis. Specific copper surface areas were determined by titration with $\mathrm{N}_{2} \mathrm{O}$ [13], using a Quantachrome ChemBET TM TPR/TPD pulse-chemisorption system interfaced to an online MKS Minilab QMS. The following procedure was adopted: (i) $0.2 \mathrm{~g}$ of catalyst was outgassed at $110^{\circ} \mathrm{C}$ for $30 \mathrm{~min}$ under $\mathrm{He}\left(20 \mathrm{ml}^{\mathrm{min}}{ }^{-1}\right)$; (ii) the catalyst was then reduced at $280^{\circ} \mathrm{C}$ for $30 \mathrm{~min}$ in flowing $10 \mathrm{vol} . \% \mathrm{H}_{2}$ in He $\left(20 \mathrm{ml}^{\mathrm{min}}{ }^{-1}\right)$; (iii) samples were cooled to $65{ }^{\circ} \mathrm{C}$, and pure $\mathrm{N}_{2} \mathrm{O}$ (Air Products) sequentially pulsed over the catalyst to react with metallic $\mathrm{Cu}$ and the resulting $\mathrm{N}_{2} \mathrm{O}$ and $\mathrm{N}_{2}$ pulses detected by mass spectrometry; (iv) complete titration was indicated by a constant $\mathrm{N}_{2} \mathrm{O}$ peak area, consistent with oxidation of all $\mathrm{Cu}$ sites. The reductive pre-treatment temperature was selected following temperature-programmed reduction experiments, which showed that exposure to $10 \mathrm{vol} . \% \mathrm{H}_{2}$ at $280{ }^{\circ} \mathrm{C}$ was sufficient to fully reduce $\mathrm{Cu}$ in all our samples (Fig. S1), in accordance with previous literature on similar sol-gel $\mathrm{Cu} / \mathrm{TiO}_{2}$ materials [14]. A 1:2 $\mathrm{N}_{2} \mathrm{O}: \mathrm{Cu}$ stoichiometry was assumed in accordance with the literature, and the final $\mathrm{Cu}$ dispersion and specific surface area were calculated according to Eqs. (1) and (2):

$\mathrm{Cu}$ dispersion $(\%)=\frac{\text { moles of } \mathrm{Cu} \text { atoms on surface }}{\text { total moles of } \mathrm{Cu} \text { atoms in sample }} \times 100$

Cu surface area $\left(\mathrm{m}^{2} \mathrm{~g}^{-1}\right)=\frac{\mathrm{N} \times \mathrm{C}}{\mathrm{M}}$

where $\mathrm{N}$ is the total number of surface $\mathrm{Cu}$ atoms, $\mathrm{C}$ is the cross section area of one $\mathrm{Cu}$ atom $\left(6.803 \times 10^{-20} \mathrm{~m}^{2}\right)$ and $\mathrm{M}$ is the bulk wt.\% of the loaded $\mathrm{Cu}$.

\subsection{Photocatalytic testing}

The photocatalytic reduction of $\mathrm{CO}_{2}$ was conducted in a stirred batch annular quartz reactor with inner capacity of $316.9 \mathrm{ml} .200 \mathrm{ml}$ of deionised water and $1 \mathrm{~g}$ of catalyst was added into this flat-bottomed quartz photo-reactor. A magnetic stirrer kept catalyst powders suspended throughout reactions. Ultra-pure gaseous $\mathrm{CO}_{2}$ (Air Products, 99.995\%) was then bubbled through the reactor for 20 min to degas the water. After purging, the reactor was pressurised with gaseous $\mathrm{CO}_{2}$ at 1 bar, and held for $15 \mathrm{~min}$ to saturate the water with $\mathrm{CO}_{2}$. The reactor was then isolated, and four 8-watt UVA (average intensity: $3.25 \mathrm{~mW} / \mathrm{cm}^{2}$, measured by UVX radiometer, UVP) lamps, located in two groups on opposing sides of the reactor, switched on to initiate photoreduction. Irradiation was stopped after 1.5-h reaction, and both gaseous and aqueous phase samples were injected into a gas chromatography equipped with a flame ionisation detector (GC/FID, Thermo-Fisher, Trace GC) to measure the concentration of the hydrocarbon product. Methane was the only organic product resulting from $\mathrm{CO}_{2}$ photoreduction within the detection limits of our method ( $200 \mathrm{ppb})$, although we cannot discount the possibility of CO formation which was undetectable on our GC. Methane yield was thus adopted as a direct measure of activity towards $\mathrm{CO}_{2}$ photocatalytic reduction. Control experiments were regularly conducted to confirm methane arose solely from $\mathrm{CO}_{2}$ photoreduction. The first control used pure $\mathrm{He}$ instead of $\mathrm{CO}_{2}$; the second operated the reactor in a dark environment; and the final control omitted the photocatalyst. No products were observed in any of these controls.

\section{Results and discussion}

\subsection{Catalyst characterization}

Diffractograms of the pure and $\mathrm{Cu}$-loaded titanias are shown in Fig. 1. Pure (pattern A) and Cu-loaded titania (patterns B-E) exhibited identical diffraction patterns to those of the anatase standard (Acros Organics, 99\%, pattern F), with no additional reflections, indicating that only crystalline anatase was present in all materials. Crystallite sizes for pure and $\mathrm{Cu}$ loaded titania catalysts were calculated from peak broadening using the Scherrer equation, and indicated similar volume-averaged particle sizes of $\sim 14 \mathrm{~nm}$ for all sol-gel prepared materials, significantly smaller than the commercial anatase $(87 \mathrm{~nm})$. Copper addition thus had negligible influence on the parent titania morphology or crystallinity.

Fig. 2 shows $\mathrm{Cu} 2 \mathrm{p}$ XP spectra of pure and selected $\mathrm{Cu} / \mathrm{TiO}_{2}$ catalysts (copper could not be detected at loadings below $0.5 \mathrm{wt} . \%$ ). For the higher loading catalysts ( $\geq 0.5 \mathrm{wt}$.\%) wherein copper was visible by XPS, the $\mathrm{Cu} 2 \mathrm{p}_{3 / 2}$ binding energy was constant at $\sim 932.4 \mathrm{eV}$ (indicative of $\mathrm{Cu}_{2} \mathrm{O}$ [15]), with only the peak intensity rising with loading. While it is not possible to confirm the presence of surface copper (I) species at lower loadings, the independence of oxidation state on nominal loading between 0.5 and $2 \mathrm{wt} . \% \mathrm{Cu}$ leads us to propose formation of a common $\mathrm{Cu}_{2} \mathrm{O}$ species across our entire series. Surface and bulk copper compositions were quantified by XPS and ICP-MS respectively,

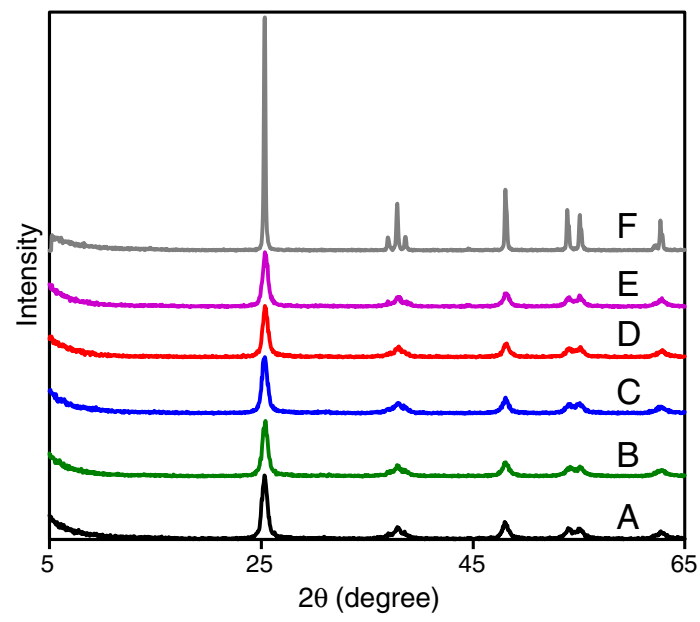

Fig. 1. XRD patterns of anatase standard, and pure and $\mathrm{Cu}$ loaded titania sol-gel catalysts: (A) Pure $\mathrm{TiO}_{2}$; (B) $0.01 \mathrm{wt} \% \mathrm{Cu} / \mathrm{TiO}_{2}$; (C) $0.03 \mathrm{wt} . \% \mathrm{Cu} / \mathrm{TiO}_{2}$; (D) $0.07 \mathrm{wt} . \% \mathrm{Cu}$ / $\mathrm{TiO}_{2}$; (E) 0.3 wt.\% $\mathrm{Cu} / \mathrm{TiO}_{2}$; and (F) Anatase standard (Acros Organics, 99\%). 


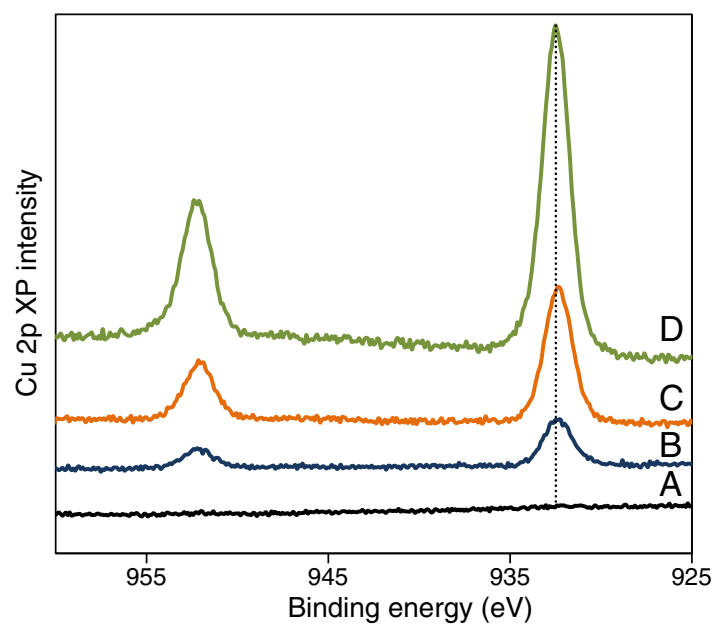

Fig. 2. Cu 2p XP spectra of: (A) Pure $\mathrm{TiO}_{2}$; (B) 0.5 wt.\% $\mathrm{Cu} / \mathrm{TiO}_{2}$; (C) 1 wt.\% Cu/TiO 2 ; and (D) $2 \mathrm{wt} . \% \mathrm{Cu} / \mathrm{TiO}_{2}$ sol-gel catalysts.

revealing significant $\mathrm{Cu}$ surface segregation with surface compositions of 1.2-8.7 wt.\% versus bulk values spanning $0.47-1.76 \mathrm{wt} . \%$, indicative of phase separated $\mathrm{Cu}_{2} \mathrm{O}$, rather than framework substituted $\mathrm{Cu}^{+}$ions.

Total surface areas of the commercial and sol-gel titanias are shown in Fig. S2 from which it is evident that Cu loading has little effect upon the textural properties of the sol-gel materials, with areas only decreasing by $10 \%$ from the parent $\mathrm{TiO}_{2}$ across the series. It is interesting to note that the lowest $(<0.02 \mathrm{wt}$.\% $\mathrm{Cu}$ ) loadings actually induce a small, but systematic increase in total surface area, before the subsequent net fall. Changes of this small magnitude are not expected to influence titania-related contributions to the resultant photoactivity [16,17], however, we believe these low loading surface area changes are a genuine effect associated with the formation of 2-dimensional $\mathrm{Cu}_{2} \mathrm{O}$ islands. In contrast to the total areas, specific copper surface areas and associated dispersions are strongly loading dependent (Fig. 3). At loadings below $0.03 \mathrm{wt} . \%, \mathrm{Cu}$ is essentially $100 \%$ dispersed, corresponding to either atomically isolated species, or 2-dimensional rafts (a partial encapsulating monolayer over the titania nanocrystallites). In the former scenario, the copper chemical environment should resemble that within a titanate, and not $\mathrm{Cu}_{2} \mathrm{O}$ as observed by XPS, hence we can discount the presence of isolated $\mathrm{Cu}$ atoms. The initial plateau in dispersion for loadings up to $0.03 \mathrm{wt}$ \%, followed by rapid fall towards zero for higher copper concentrations, strongly suggests the existence of two growth regimes: 2-dimensional $\mathrm{Cu}_{2} \mathrm{O}$ island growth for loadings between 0.01 and

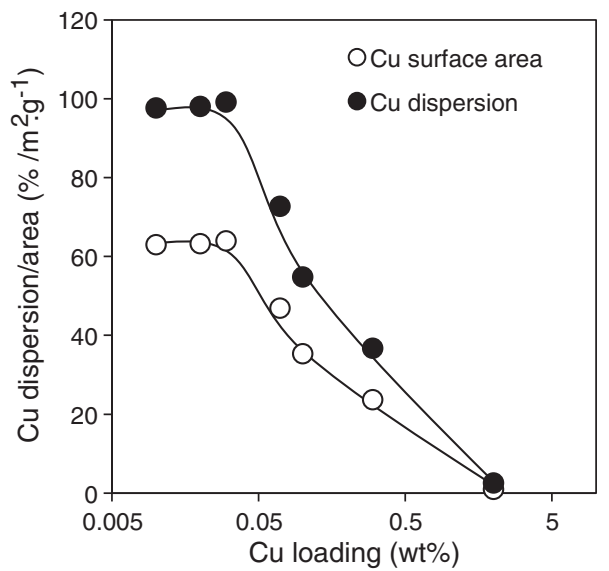

Fig. 3. Copper dispersion and specific surface area of $\mathrm{Cu} / \mathrm{TiO}_{2}$ sol-gel catalysts as a function of nominal bulk $\mathrm{Cu}$ loading.
0.03 wt.\%; and subsequent genesis and growth of 3-dimensional $\mathrm{Cu}_{2} \mathrm{O}$ nanoparticles. This transition point occurs at very low effective Cu coverages, far below the nominal full monolayer, evidencing a Volmer-Weber growth mode, and poor wetting of titania by copper oxide as observed by STM [18] and XPS [19] over rutile $\mathrm{TiO}_{2}(110)$. Nucleation, growth and coalescence of oxide and metal nanoparticle on planar and porous substrates are complex processes [20-22], where we hope to utilise scanning probe microscopy and in-situ XAS to further investigate the atomic-scale structure of our $\mathrm{Cu}_{2} \mathrm{O}$ nanostructures in the future.

\subsection{Photocatalytic activity}

$\mathrm{CO}_{2}$ photoreduction was performed for $1.5 \mathrm{~h}$ during UVA irradiation and the resulting correspondence between methane yields and $\mathrm{Cu}$ dispersion/surface area is presented in Fig. 4. A strong volcano dependence of photoactivity for methane production with copper loading was observed for the sol-gel materials, wherein the $\mathrm{CH}_{4}$ yield of the best-performing $0.03 \mathrm{wt} . \% \mathrm{Cu} / \mathrm{TiO}_{2}$ catalyst was exhibited a 10 fold rate-enhancement over that of undoped titania. Since the mean $\mathrm{TiO}_{2}$ crystallite sizes are all close to the optimal value $(14 \mathrm{~nm})$ for $\mathrm{CO}_{2}$ photoreduction [23], and in common with their total surface areas, show little variance across the series, this pronounced effect cannot be attributed to geometric differences in the titania support. The extremely low copper concentrations necessary to achieve such promotion, with the maximum yield attained at only $400 \mathrm{ppm} \mathrm{Cu}$, is especially striking, and also indicates a phenomenon arising from the promoter phase, rather than changes in the bulk properties of the titania parent. Fig. 4 demonstrates that $\mathrm{CO}_{2}$ photoreduction is strongly associated with the exposed $\mathrm{Cu}_{2} \mathrm{O}$ surface area; methane yield tailing off coincident with the switchover from 2-dimensional islands to 3-dimensional $\mathrm{Cu}_{2} \mathrm{O}$ crystallites. It is interesting to note the different selectivity reported for higher loading $\mathrm{Cu} / \mathrm{TiO}_{2}$ photocatalysts prepared via a similar sol-gel route [6], wherein methanol and not methane was the primary product of $\mathrm{CO}_{2}$ photoreduction. Although the origin of this copper loading dependence requires further investigation, it may reflect band gap broadening with $\mathrm{Cu}_{2} \mathrm{O}$ crystallite size, affording more energetic photo-excited electrons necessary to drive the more thermodynamically difficult reduction of $\mathrm{CO}_{2}$ to methanol $\left(\mathrm{E}_{\text {redox }}^{\mathrm{o}}=-0.38 \mathrm{~V}\right.$ vs. NHE, compared with $-0.28 \mathrm{~V}$ for methane production) [4]. Peak methanol production reported in reference [6] $(780 \mathrm{nmol} / \mathrm{h} / \mathrm{g})$ is also substantially higher than our best methane productivity $(24 \mathrm{nmol} / \mathrm{h} / \mathrm{g})$, reflecting the widely disparate reaction conditions employed; specifically, the use of higher energy UVC in reference [6], which also utilised internal reactor illumination (resulting in a higher photon flux to the catalyst), and

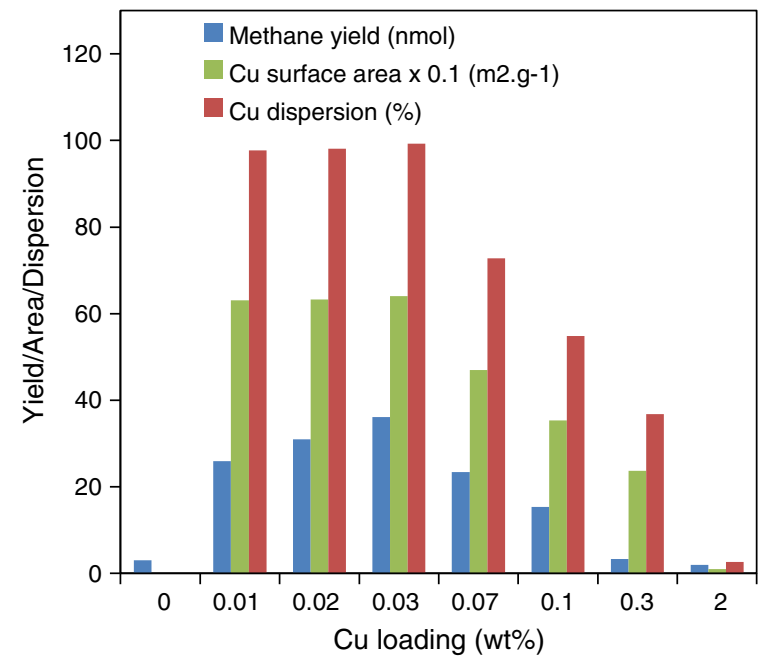

Fig. 4. Correspondence between $1.5 \mathrm{~h} \mathrm{CH}_{4}$ yield from $\mathrm{CO}_{2}$ photoreduction over $\mathrm{Cu} / \mathrm{TiO}_{2}$ sol-gel catalysts and $\mathrm{Cu}$ surface area and dispersion. 
crucially added $\mathrm{NaOH}$ to the reaction mixture to act as hole-scavengers suppressing recombination, all of which served to enhance methanol production.

\subsection{Possible mechanism of copper promotion}

It has been previously postulated that $\mathrm{Cu}^{+}$dopants (as free ions or the oxide) could serve as traps for photoexcited electrons or holes arising from $\mathrm{TiO}_{2}$ [24,25]. Such electron-hole exchange could also occur between $\mathrm{Cu}_{2} \mathrm{O}$ nanostructures and $\mathrm{TiO}_{2}$ in this work, slowing slow $\mathrm{e}^{-}-\mathrm{h}^{+}$recombination within the parent titania and thereby increasing the probability of electron transfer to adsorbed $\mathrm{CO}_{2}$ and the genesis of reactive intermediates such as ${ }^{-} \mathrm{CO}_{2}^{-}$and $\mathrm{HCOO}^{-}$[26-28]. Such charge-trapping is expected to be heavily influenced by the nature of the heterojunction interface between $\mathrm{Cu}_{2} \mathrm{O}$ and $\mathrm{TiO}_{2}$, with 2-dimensional copper oxide islands facilitating rapid charge migration from the underlying titania substrate (for subsequent $\mathrm{CO}_{2}$ and water activation), while minimising the potential for bulk $\mathrm{e}^{-}-\mathrm{h}^{+}$recombination within 3-dimensional $\mathrm{Cu}_{2} \mathrm{O}$ crystallites [29,30]. If surface $\mathrm{Cu}_{2} \mathrm{O}$ species are indeed the active centre for $\mathrm{CO}_{2}$ photoreduction, then one would anticipate a linear correlation between photoactivity and $\mathrm{Cu}$ dispersion, precisely as seen in Fig. 5. It is important to recall that the band gap of $\mathrm{Cu}_{2} \mathrm{O}$ lies in the visible, and thus may itself undergo direct photoexcitation upon UVA or solar irradiation, contributing to methane production. However, at the extremely low $\mathrm{Cu}$ concentrations found to be optimal within this study, it seems more probably that $\mathrm{Cu}_{2} \mathrm{O}$ acts as an intermediary in $\mathrm{CO}_{2}$ photoreduction, trapping and stabilising a high flux of photoexcited electrons created on titania, for transport to adsorbed carbon dioxide.

A recent in-situ DRIFTS study utilising isotopically-labelled ${ }^{13} \mathrm{CO}_{2}$ showed that surface carbon impurities may act as a carbon source for the production of reactively-formed hydrocarbons from $\mathrm{CO}_{2}$ photocatalysis over titania, via the reverse Boudouard reaction, and corresponding intermediate $\mathrm{CO}$ formation [31]. Although Yui and co-workers have since used isotopic-labelling to unequivocally demonstrated that $\mathrm{CO}_{2}$ can indeed be photoreduced to methane over $\mathrm{TiO}_{2}$ and $\mathrm{Pd} / \mathrm{TiO}_{2}$ [32], the question remains as to what extent the reverse Boudouard reaction (4) competes with direct $\mathrm{CO}_{2}$ photoreduction (3) as a source of methane, or indeed whether direct photo-oxidation of surface carbon may occur (5).

$\mathrm{CO}_{2}+2 \mathrm{H}_{2} \mathrm{O} \rightarrow \mathrm{CH}_{4}+2 \mathrm{O}_{2}$ true photosynthesis via directCO 2 photoreduction (3)

$\mathrm{CO}_{2}+\mathrm{C}_{\mathrm{a}} \rightarrow 2 \mathrm{CO}$ reverse Boudouard reaction (surface $\mathrm{C}$ participation)

$\mathrm{H}_{2} \mathrm{O}+\mathrm{C}_{\mathrm{a}} \rightarrow \mathrm{CO}+\mathrm{H}_{2}$ photo - oxidation of surface carbon (no $\mathrm{CO}_{2}$ participation) (5)
The last scenario, namely whether methane arise from photooxidation of surface carbon by water (the only possible process by which it could form without direct participation of $\mathrm{CO}_{2}$ ) can be easily discounted by a simple control experiment in which we exposed our catalysts to water and UV light in the absence of $\mathrm{CO}_{2}$, resulting in negligible methane. This definitively proves that photo-activated $\mathrm{CO}_{2}$ is an essential reactant in our methane production, as first postulated by Inoue and co-workers [33] and demonstrated by isotope-labelling experiments [31,34], enabling us to discount reaction (5). In order to assess the likely contribution of reaction (4), i.e. surface carbon assisted $\mathrm{CO}_{2}$ photoreduction, to our observed methane yield, we examined the relationship between methane production and the initial surface carbon concentration of our as-prepared $\mathrm{Cu} / \mathrm{TiO}_{2}$ catalysts from XPS. Fig. 6 reveals a strong inverse correlation between carbon impurities on our as-prepared catalysts and methane production. While this does not conclusively prove that surface carbon plays no role in our observed photocatalysis, it offers strong evidence that the major route to reactively-formed methane is via direct $\mathrm{CO}_{2}$ photoreduction and not carbon-assisted reverse disproportionation. It is important to note that the goal of this communication is not to elucidate the global reaction pathway in $\mathrm{CO}_{2}$ photoreduction, but rather, to identify key structural aspects in $\mathrm{Cu}$-doped $\mathrm{TiO}_{2}$ photocatalysts to guide future materials design and thereby engineer improved methane production. Future isotope studies would be welcome to quantify the extent of any possible minor contributions from reaction (4).

\section{Conclusions}

Copper-loaded titania photocatalysts, prepared via a one-pot, solgel synthesis, comprise highly dispersed and surface localised $\mathrm{Cu}_{2} \mathrm{O}$ nanostructures decorating $14 \mathrm{~nm}$ anatase crystallites. $\mathrm{Cu}_{2} \mathrm{O}$ strongly promotes $\mathrm{CO}_{2}$ photoreduction to methane under UVA light, with up to 10 -fold rate-enhancements over the analogous unloaded anatase. This promotion is strongly linked to the nature of the dispersed copper oxide morphology, with 2-dimensional islands proposed both as trapping centres for anatase photoexcited charge carriers, and the primary active site responsible for $\mathrm{CO}_{2}$ photoreduction. Formation of $\mathrm{Cu}_{2} \mathrm{O}$ multilayers/nanoparticles at $\mathrm{Cu}$ loadings $>0.03 \mathrm{wt}$.\% limits the magnitude of this promotion, possible reflecting increased $\mathrm{e}^{-}-\mathrm{h}^{+}$recombination within the bulk of 3-dimensional copper oxide crystallites. There is no evidence that reactively-formed methane arises from the reverse disproportionation reaction of $\mathrm{CO}_{2}$ with surface carbon, although we cannot discount minor contributions from such a reverse Boudouard process.

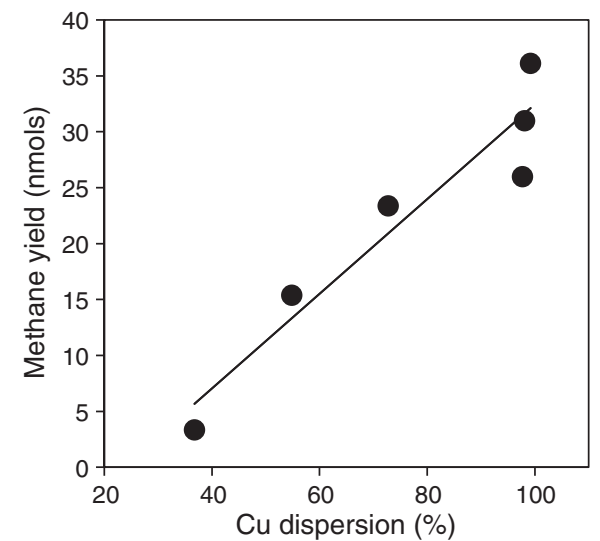

Fig. 5. Linear correlation between $\mathrm{CH}_{4}$ yield and $\mathrm{Cu}$ dispersion over $\mathrm{Cu} / \mathrm{TiO}_{2}$ sol-gel catalysts.

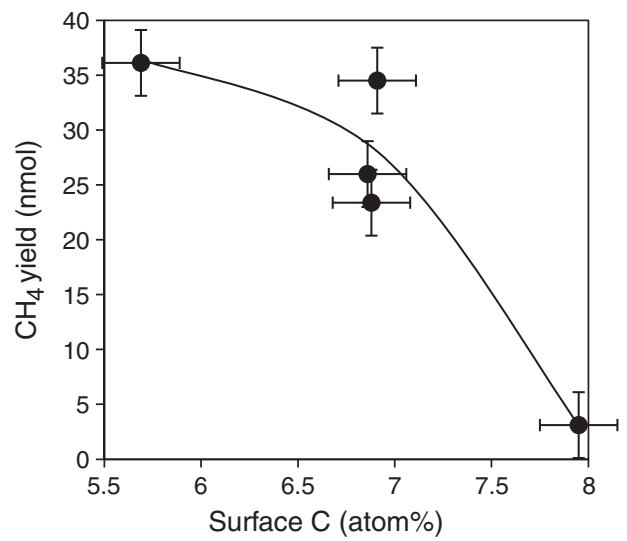

Fig. 6. Inverse correlation between $1.5 \mathrm{~h} \mathrm{CH}_{4}$ yield from $\mathrm{CO}_{2}$ photoreduction over $\mathrm{Cu}$ / $\mathrm{TiO}_{2}$ sol-gel catalysts and surface carbon content. 


\section{Acknowledgements}

The authors acknowledge support from the Centre for Innovation in Carbon Capture and Storage (Engineering and Physical Sciences Research Council grant EP/F012098/1). This work was financially supported by the National Science Council under the project of NSC 98-2911-I-002-061 and The Royal Society International Project (JP090075). We thank Dr. Karen Wilson, Cardiff University, for XPS analysis. Y. Fernández is grateful to CSIC and FICYT of Spain for financial support under the Programme "Clarín" 2011-2012. AFL thanks the EPSRC (EP/G007594/2) for financial support and a Leadership Fellowship. MMV is grateful for support received through a Philip Leverhulme Prize.

\section{Appendix A. Supplementary data}

Supplementary data to this article can be found online at doi:10. 1016/j.catcom.2012.03.025.

\section{References}

[1] D. Luthi, M. Le Floch, B. Bereiter, T. Blunier, J.M. Barnola, U. Siegenthaler, D. Raynaud, J. Jouzel, H. Fischer, K. Kawamura, T.F. Stocker, Nature 453 (2008) 379-382.

[2] F. Bowen, Energy Policy 39 (2011) 2256-2264

[3] G. Centi, S. Perathoner, Catalysis Today 148 (2009) 191-205.

[4] V.P. Indrakanti, J.D. Kubicki, H.H. Schobert, Energy \& Environmental Science (2009) 745-758

[5] K. Ikeue, H. Yamashita, M. Anpo, T. Takewaki, The Journal of Physical Chemistry. B 105 (2001) 8350-8355.

[6] I.H. Tseng, W.C. Chang, J.C.S. Wu, Applied Catalysis B: Environmental 37 (2002) 37-48.

[7] Y. Li, W.N. Wang, Z. Zhan, M.H. Woo, C.Y. Wu, P. Biswas, Applied Catalysis B: Environmental 100 (2010) 386-392.

[8] H. Yamashita, H. Nishiguchi, N. Kamada, M. Anpo, Research on Chemical Intermediates 20 (1994) 823-825.

[9] J.C.S. Wu, I.H. Tseng, W.C. Chang, Journal of Nanoparticle Research 3 (2001) 113-118.
[10] J.C.S. Wu, Y. Yeh, Journal of Materials Research 16 (2001) 2-x.

[11] T. Lindgren, J.M. Mwabora, E. Avendano, J. Jonsson, A. Hoel, C. Granqvist, S. Lindquist, The Journal of Physical Chemistry. B 107 (2003) 5709-5716.

[12] B.G. Yacobi, Semiconductor materials: an introduction to basic principles, 7 , Kluwer Academic/Plenum Publishers, New York, 2003, pp. 183-208.

[13] G.C. Chinchen, C.M. Hay, H.D. Vandervell, K.C. Waugh, Journal of Catalysis 103 (1987) 79-86.

[14] I.-H. Tseng, J.C.S. Wu, H.-Y. Chou, Journal of Catalysis 221 (2004) 432-440.

[15] Z.H. Gan, G.Q. Yu, B.K. Tay, C.M. Tan, Z.W. Zhao, Y.Q. Fu, Journal of Physics D 37 (2004) 81-85.

[16] Y. Jung, S.B. Park, Applied Catalysis B: Environmental 25 (2000) 249-256.

[17] G.H. Tian, H.G. Fu, L.Q. Jing, B.F. Xin, K. Pan, Journal of Physical Chemistry C 112 (2008) 3083-3089.

[18] J. Zhou, Y.C. Kang, D.A. Chen, The Journal of Physical Chemistry. B 107 (2003) 6664-6667.

[19] L. Huang, F. Peng, F.S. Ohuchi, Surface Science 603 (2009) 2825-2834

[20] Chun-Ming Li, I.M. Robertson, M.L. Jenkins, J.L. Hutchison, R.C. Doole, Micron 36 (2005) 9-15.

[21] E.V. Zolotukhina, T.A. Kravchenko, Electrochimica Acta 56 (2011) 3597-3604

[22] K. Højrup-Hansen, S. Ferrero, C.R. Henry, Applied Surface Science 226 (2004) $167-172$.

[23] K. Koci, L. Obalova, L. Matejova, D. Placha, Z. Lacny, J. Jirkovsky, O. Solcova, Applied Catalysis B: Environmental 89 (2009) 494-502.

[24] M. Ni, M.K.H. Leung, D.Y.C. Leung, K. Sumathy, Renewable and Sustainable Energy Reviews 11 (2007) 401-425.

[25] M.I. Litter, Applied Catalysis B: Environmental 23 (1999) 89-114.

[26] H.J. Cardona, C. del Moral, C.R. Cabrera, Journal of Electroanalytical Chemistry 513 (2001) 45.

[27] O. Koga, T. Matsuo, N. Hoshi, Y. Hori, Electrochimica Acta 44 (1998) 903.

[28] Y. Hori, A. Murata, T. Tsukamoto, H. Wakebe, O. Koga, H. Yamazaki, Electrochimica Acta 39 (1994) 2495.

[29] Z. Zhang, C.C. Wang, R. Zakaria, J.Y. Ying, The Journal of Physical Chemistry. B 102 (1998) 10871-10878.

[30] W. Choi, A. Termin, M.R. Hoffmann, Journal of Physical Chemistry 98 (1994) 13669-13679.

[31] C.-C. Yang, Y.-H. Yu, B. van der Linden, J.C.S. Wu, G. Mul, Journal of the American Chemical Society 132 (2010) 8398-8406.

[32] T. Yui, A. Kan, C. Saitoh, K. Koike, T. Ibusuki, O. Ishitani, Applied Materials \& Interfaces 3 (2011) 2594-2600.

[33] T. Inoue, A. Fujishima, S. Konishi, K. Honda, Nature 277 (1979) 637-638.

[34] N. Ulagappan, H. Frei, Journal of Physical Chemistry A 104 (2000) 7834-7839. 